\title{
MCMURRAY OSTEOTOMY
}

\author{
With a Note on the " Regeneration" of Articular Cartilage*
}

\author{
Robert H. C. Robins, Exeter, England, and James Piggot, Londonderry, \\ NORTHERN IRELAND \\ From the Princess Elizabeth Orthopaedic Hospital, Exeter, Devon
}

Arthrodesis is usually the best operation for a relatively young patient with osteoarthritis of one hip caused by previous injury or disease. It is also a satisfactory solution in an older patient with a single painful hip in which stiffness is a dominant factor. Unfortunately, many patients with disabilities arising from the hip do not fall into either of these categories, particularly those with bilateral osteoarthritis or with stiffness in the lumbar spine and those with an ununited fracture of the femoral neck. These are the patients for whom arthroplasty held high hopes, but as the various operations for prosthetic replacement have been found wanting, interest has been renewed in the intertrochanteric osteotomy with which the name of McMurray (1935) has become closely associated. The purposes of the operation are to relieve pain and to correct deformity while at the same time preserving such movement as exists. The satisfactory, if unspectacular, results which can be expected have recently been the subject of several reports (Osborne and Fahrni 1950; Campbell and Jackson 1955; Wardle 1955; Adam and Spence 1958; Burrows, Murley and Shephard 1955).

The purpose of this paper is to report a series of results in which the tracing of patients is almost complete, with emphasis on the following points: 1) the influence of internal fixation upon the progress after operation; 2) the results according to the indications for operation; and 3) the late radiographic appearances of the hip joint.

No satisfactory single explanation for the relief of pain after osteotomy has been advanced. McMurray based his operation on the bifurcation principle which had been developed by Lorenz (1919) and von Baeyer (1918). These workers in company with Schanz (1922) considered that the essential factor was the provision of pelvic support through the shaft of the femur. The whole problem has been the subject of a review by Milch (1947).

TABLE I

Conditions for which Operation was Performed

\begin{tabular}{|c|c|c|c|c|}
\hline \multicolumn{4}{|c|}{ Condition } & \multirow{2}{*}{$\begin{array}{c}\begin{array}{c}\text { Number of } \\
\text { operations }\end{array} \\
58\end{array}$} \\
\hline Osteoarthritis. & . & $\cdot$ & . & \\
\hline Ununited fracture & . & ${ }^{\circ}$ & . & 19 \\
\hline \multicolumn{4}{|c|}{ Avascular necrosis after fracture } & 5 \\
\hline
\end{tabular}

McMurray (1939) believed that pain was relieved on account of the altered thrust of weight bearing, and that the adducted position of the femoral head brought a different part of the articular cartilage in contact with the weight-bearing area of the acetabulum. Malkin (1936) stated that division of the bone and correction of deformity by simple osteotomy without displacement was sufficient, and Capener (1956) noted the mechanical factor of upward thrust from the periphery as well as the transmission of body weight downwards. To these views must be added the possibility of altering the vascular supply to the femoral head.

* Presented at the Spring Meeting of the British Orthopaedic Association in Exeter, May 1959. 
The radiographic studies of the factors which may be important as contributing to the success of the operation are: 1) the position of the upper fragment, which relates also to the theory of the Pauwels osteotomy; 2) the degree of medial displacement at the osteotomy site; and 3) the apparent increase in joint space which has often been observed and interpreted as regeneration of articular cartilage.

Adam and Spence (1958) threw doubt on the importance of the first, and Malkin's work suggests that the second is not essential. We have no contributions to make on these aspects, but we have made a study of the changing appearances of the joint space before and after operation.

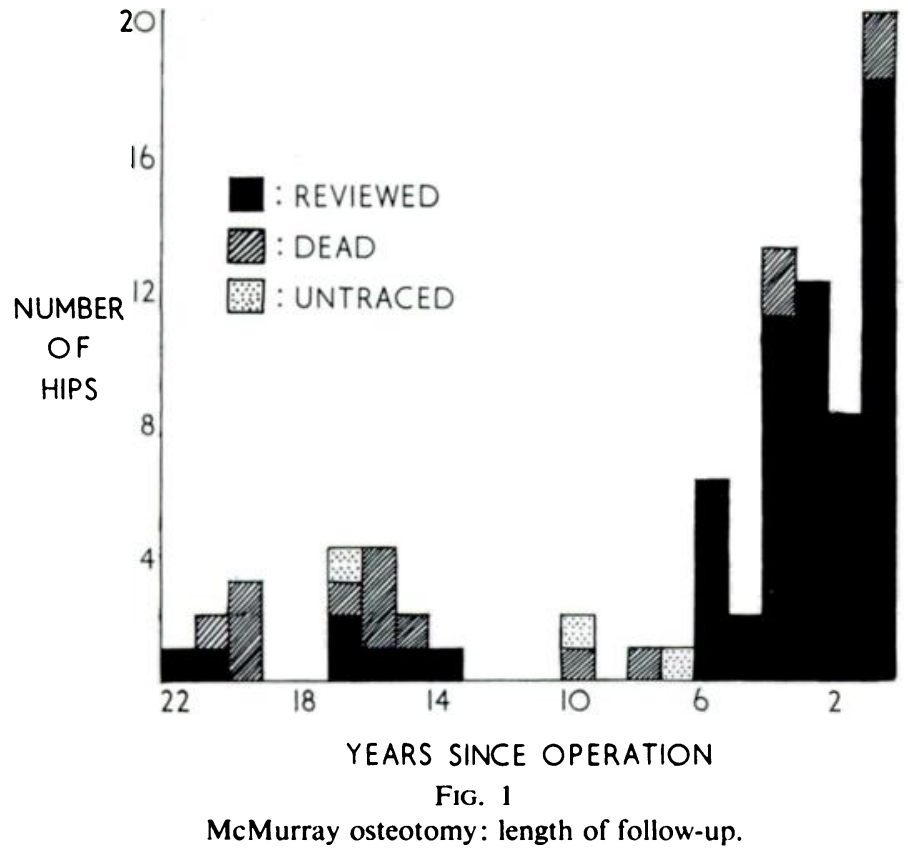

CLINICAL MATERIAL

In the past twenty-two years the operation has been performed at the Princess Elizabeth Orthopaedic Hospital, Exeter, eighty-two times in eighty-one patients, all but three of whom have been traced (Table I). Corrective osteotomies for coxa vara have not been included. Figure 1 indicates the length of follow-up. The average age at operation was sixty years, and it is therefore not surprising that fifteen patients have since died, fourteen of them from causes unconnected with the operation.

It is generally accepted that the type of painful osteoarthritic hip most suited to this procedure is one that combines deformity with a reasonable range of movement in flexion and adduction. Nevertheless, several osteotomies were performed on hips with very limited movement, and a number might well be described as "salvage operations" upon patients who by reason of their hips or their general medical condition were considered unfit for other major reconstructive procedures. Severnl such patients were crippled by non-union of a fractured femoral neck.

Operative technique-This differed slightly according to the operating surgeon, but in all cases the line of osteotomy was intertrochanteric and the shaft fragment was displaced medially and abducted. When necessary a lateral wedge of bone was removed. Internal fixation of the osteotomy was introduced in 1951, and, since then, this has been the method of choice. The usual device was a Capener nail-plate modified to conform with the obtuse angle required, but on several occasions a Lipmann Kessel plate was used. An adductor tenotomy was 
TABLE II

Complications after Operation

\begin{tabular}{|ll|}
\hline \multicolumn{1}{|c|}{ Complication } & Number of cases \\
\hline Wound haematoma $\cdot$ & $\cdot$ \\
\hline Pulmonary collapse $\cdot$ & $\cdot$ \\
\hline Urinary retention $\cdot$ & $\cdot$ \\
\hline Venous thrombosis $\cdot$ & $\cdot$ \\
\hline Ileus $\cdot$ & $\cdot$
\end{tabular}

TABLE III

The Influence of Internal Fixation on Course After Operation

\begin{tabular}{|c|c|c|}
\hline & Before 1951 & Since 1951 \\
\hline Average time in plaster (days) & 116 & 84 \\
\hline Average stay in hospital (days) . & 106 & 60 \\
\hline $\begin{array}{l}\text { Less than } 90 \text { degrees of knee movement } \\
\text { (percentage of patients reviewed) }\end{array}$ & 23 & 6 \\
\hline
\end{tabular}

TABLE IV

Relation of Results to Indications for Operation

\begin{tabular}{|c|c|c|c|c|}
\hline \multicolumn{5}{|c|}{ Number of hips } \\
\hline & Osteoarthritis & $\begin{array}{l}\text { Ununited } \\
\text { fracture }\end{array}$ & $\begin{array}{c}\text { Avascular } \\
\text { necrosis }\end{array}$ & Total \\
\hline Excellent & 10 & 5 & 0 & 15 \\
\hline Good & 22 & 2 & 0 & 24 \\
\hline Fair & 9 & 3 & 2 & 14 \\
\hline Poor & 8 & 0 & 3 & 11 \\
\hline & 111 & 10 & 5 & 64 \\
\hline
\end{tabular}

TABLE V

Results in the Whole Series

\begin{tabular}{|c|c|c|}
\hline & $\begin{array}{c}\text { Results (including mobility) } \\
\text { (percentage) }\end{array}$ & $\begin{array}{c}\text { Results (excluding mobility) } \\
\text { (percentage) }\end{array}$ \\
\hline Excellent & 23 & 40 \\
\hline Good . & 38 & 37 \\
\hline Fair & 22 & 12 \\
\hline Poor & 17 & 11 \\
\hline
\end{tabular}


sometimes performed. It is the present practice in this hospital for patients to wear a long hip spica for six weeks after operation, and a short one with the knee free for another six weeks. They are stood out of bed as soon as possible after operation, and start walking with crutches at about three weeks. Reliance upon internal fixation without the added support of plaster did not prove satisfactory. In cases of osteoarthritis, unlike those of pertrochanteric fracture, the hip is limited in movement and the extra strain thrown on the site of osteotomy causes pain. On one occasion the nail-plate lost its hold on the upper fragment.

Mortality-One patient died from pulmonary embolism two months after operation.

Complications-These are shown in Table II. None caused permanent disability.

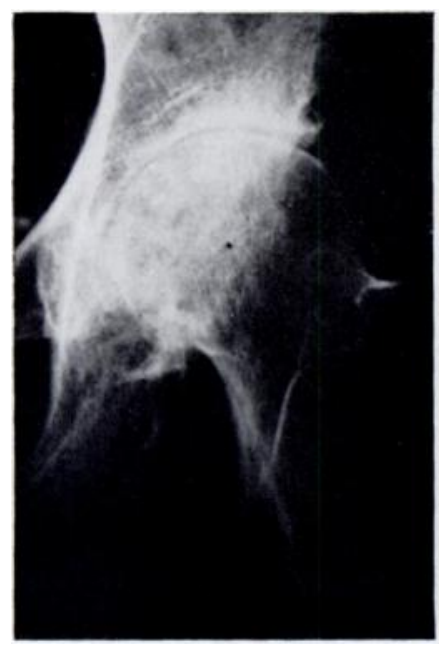

FIG. 2

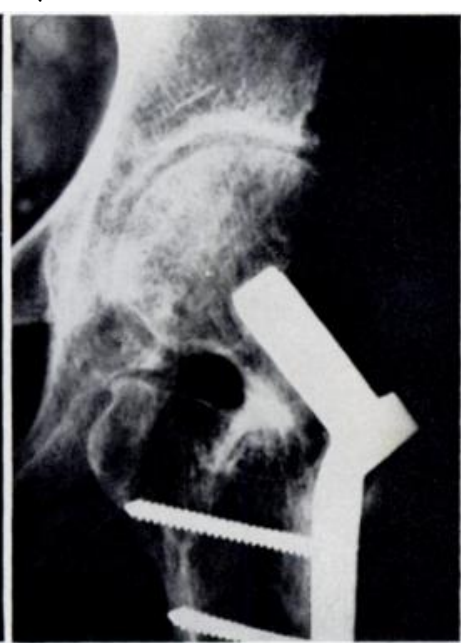

Fig. 3

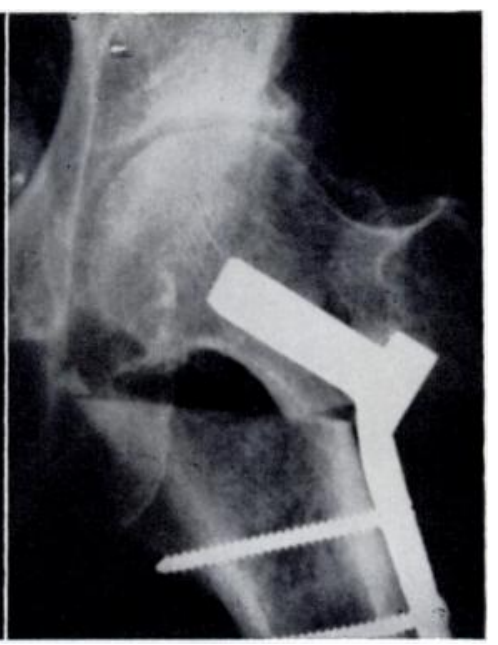

Fig. 4

Apparent increase in joint space after osteotomy. Figure 2-Osteoarthritis of the hip. Figure 3-The same hip fifteen months after McMurray osteotomy, showing apparent increase in joint space. Figure 4-The same hip two days after operation showing similar appearances and indicating that these are due to change of position of the femoral head.

\section{RESULTS}

These will be described in relation to internal fixation and radiographic appearances as well as to the clinical assessment of the patients. If the patients who had died or could not be traced are discounted, sixty-four hips were available for review.

Influence of internal fixation-The main benefits have been to shorten the time in plaster and the length of stay in hospital (Table III). The incidence of stiffness of the knee has been reduced.

In four patients fibrous union of the osteotomy followed internal fixation though there was not necessarily a causal relation; only one of these patients complained of pain. In the clinical assessment no significant difference was noted between patients treated by internal fixation and a single hip spica, and those in whom the fixation was entirely external (the latter were a smaller group).

Results in relation to indications for operation-Assessment was made in four categories, as recommended by Shepherd (1954): 1) relief of pain; 2) patient's own assessment; 3) function by performance in which black marks were given for failure to reach a given standard; 4) Gade's mobility index.

Two difficulties were met. First, the limiting factor in function was often the opposite hip or such medical complications as cardiac failure or hemiplegia. It was felt that some allowance should be made for this in grading the results, but the result was seldom rated higher than fair. It is, however, these complicating factors which make assessment difficult and limit the value of comparison with other series. This applies particularly when the scope

vol. 42 B, No. 3, AUGUST 1960 
of the operation has been extended to include patients for whom no procedure could be expected to produce an excellent result.

The second problem concerns mobility. The prime objects of osteotomy are relief of pain and correction of deformity. Shepherd's method of assessment was designed for arthroplasty, in which mobility is an essential aim of the procedure. With a McMurray osteotomy

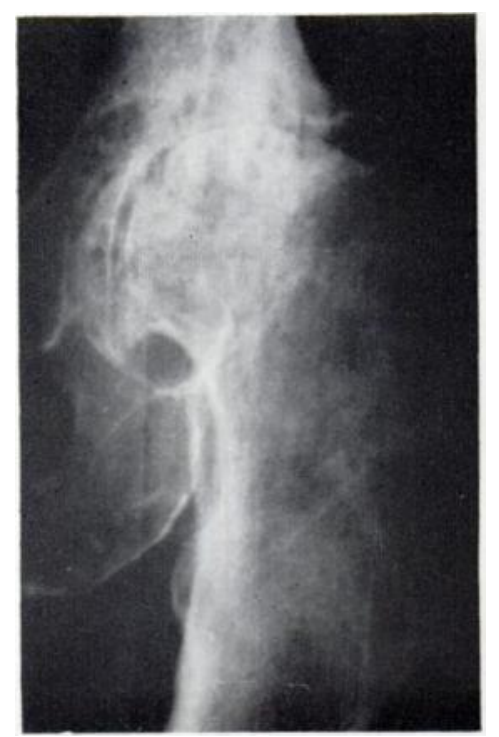

Fig. 5

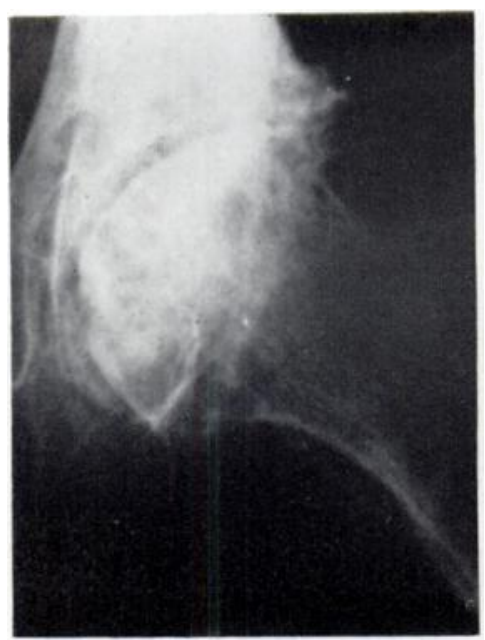

Fig. 7

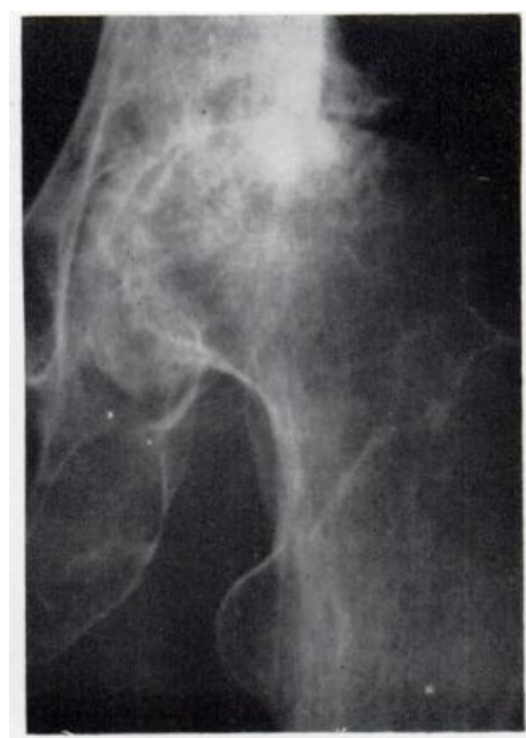

FIG. 6

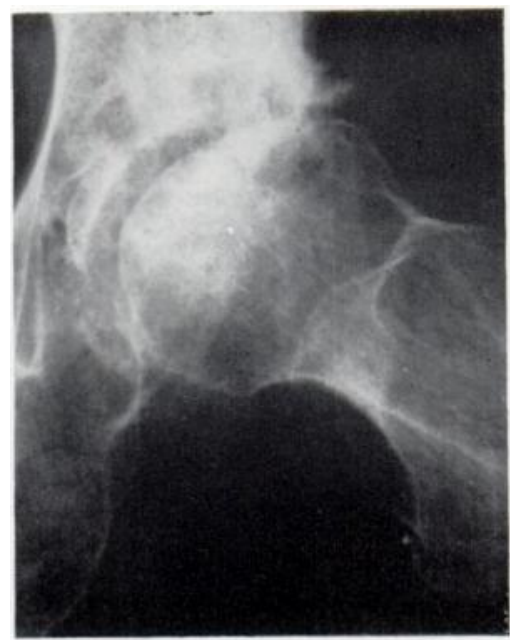

FIG. 8

Osteoarthritis of the hip. Radiographs taken in different positions of the limb showing alteration of the size of the joint space. Figure 5-Adduction with medial rotation. Figure 6-Adduction with lateral rotation. Figure 7-Abduction with medial rotation. Figure 8-Abduction with lateral rotation.

it is hoped to preserve such movement as already exists. but when the operation has been performed on hips with very limited movement the results on this classification can only be graded as fair or poor. Eight such hips proceeded to bony fusion. For this reason a second assessment was made, excluding mobility, and a third in which only the relief of pain and the patient's views were considered.

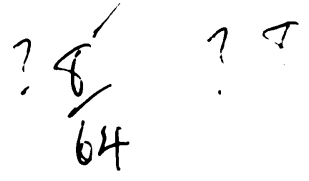

THE JOURNAL OF BONE AND JOINT SURGERY 
Table IV gives the results according to the reasons for operation. Although the figures are small it is important to note, first, the poor results for old transcervical fractures with avascular necrosis, and, secondly, the good relief of pain in ununited fractures. The

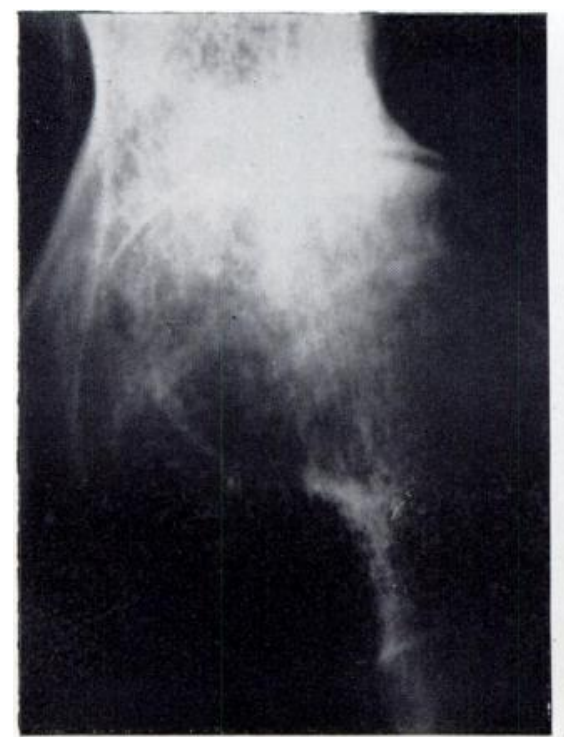

FiG. 9

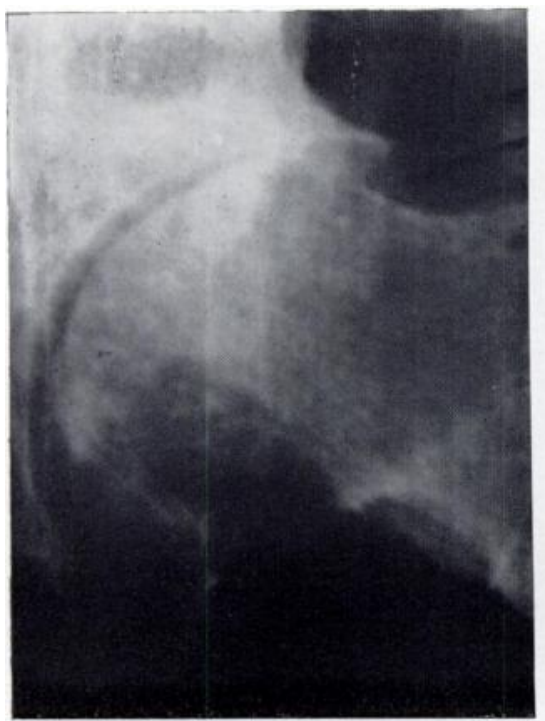

FIG. 11

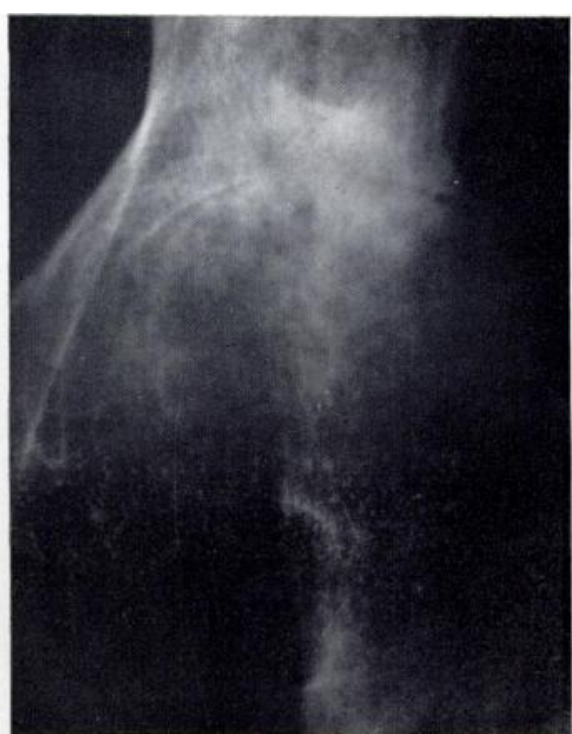

FIG. 10

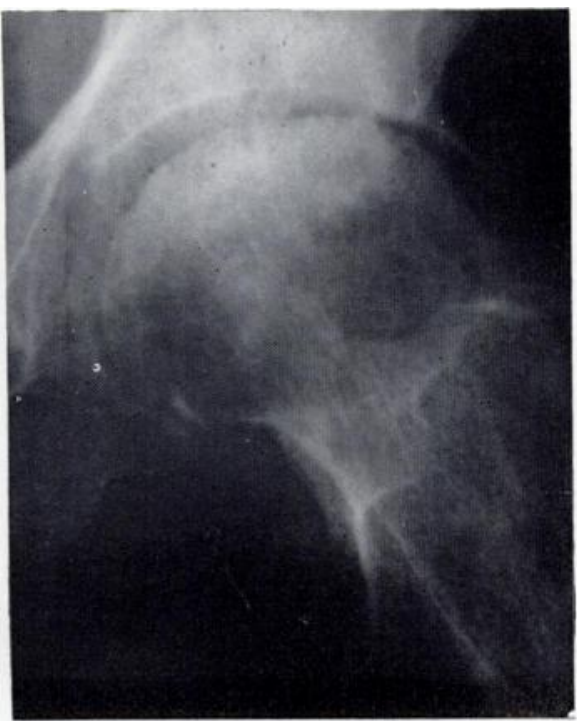

FIG. 12

Osteoarthritis of the hip. Radiographs taken in different positions of the limb showing alteration of the size of the joint space. Figure 9-Adduction with medial rotation. Figure 10-Adduction with lateral rotation. Figure 11-Abduction with medial rotation. Figure 12-Abduction with lateral rotation.

distribution of results was unrelated to the length of follow-up and no late recurrence of pain was found; the poor results were apparent early.

Table $\mathrm{V}$ gives the results of all cases, expressed in percentages and compared with the assessment from which mobility was excluded. Judged solely on the patient's assessment of relief of pain-in fact, on whether the operation was worthwhile-92 per cent claimed 
improvement and 8 per cent that their symptoms were unchanged or worse. These figures agree closely with those of Adam and Spence (1958).

Improvement in the radiographic appearances-This has been noted by previous authors (Osborne and Fahrni 1950, Wardle 1955). Adam and Spence (1958) stated that thirty-eight out of fifty-five hips for which radiographs before and after operation were available showed

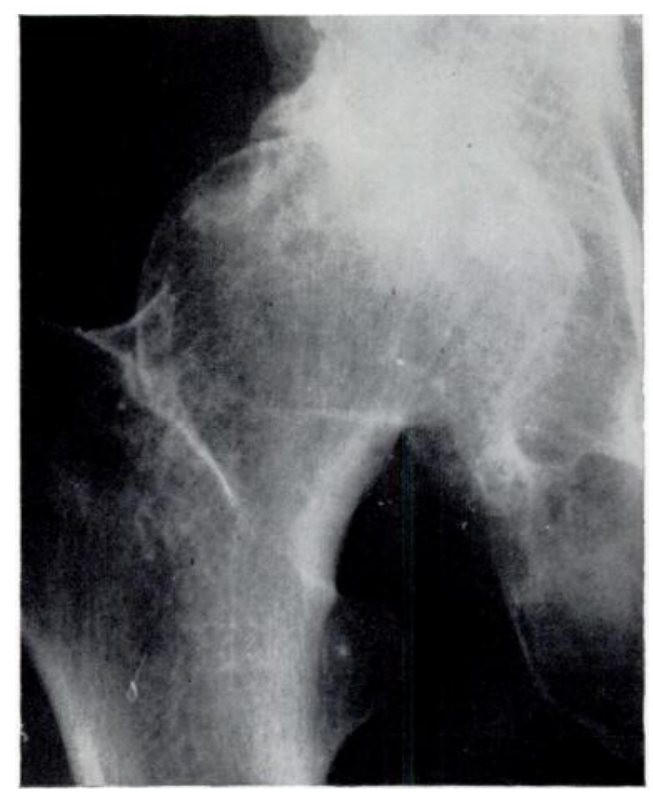

FIG. 13
FIGs. 13 To 17

Osteoarthritis of the hip showing true increase in joint space in radiographs taken three years after operation. Figure 13-Before operation. Figures 14 to 17 -The same hip three years after operation. Figure 14-Adduction with medial rotation. Figure 15-Adduction with lateral rotation. Figure 16Abduction with medial rotation. Figure 17Abduction with lateral rotation.

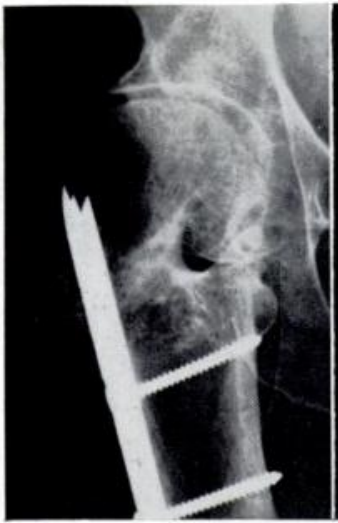

FIG. 14

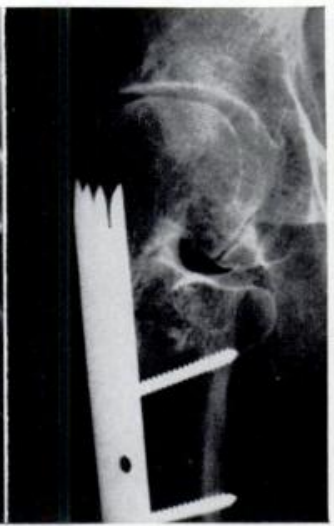

FIG. 15

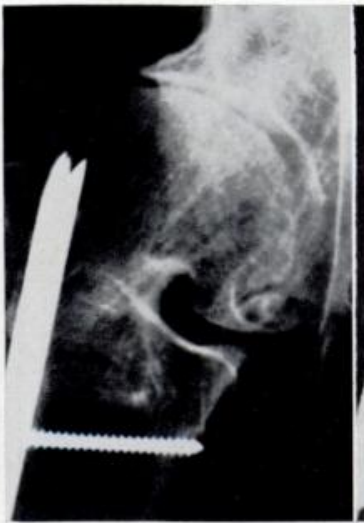

FIG. 16

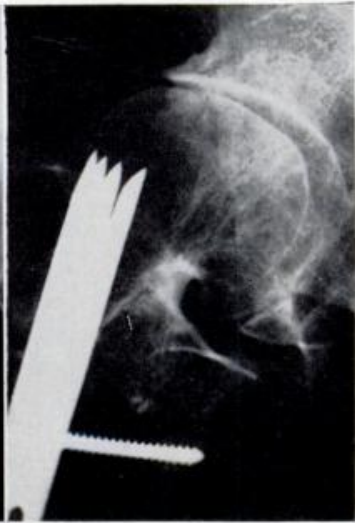

FIG. 17

an increase in joint space and regression of osteoarthritis. This prompts the question whether these are real changes due to regeneration of articular cartilage or whether the apparent increase in joint space results from the altered position of the hip. In reviewing the radiographs of the patients whose operations were performed for osteoarthritis, fifteen were found to show some apparent increase in at least one of the films taken after operation, but twelve of these did not stand up to careful scrutiny. Several had an improvement in the joint space in the film taken immediately after operation (Figs. 2 to 4 ) which could only be due to the change of position of the femoral head after osteotomy. In cases of doubt views were taken with the hip in various positions, care being exercised to avoid applying traction to the 
limb. To prove the point, twelve patients with osteoarthritis of the hip who had not undergone surgery were subjected to radiography with the hips in comparable positions, six under anaesthesia and six without, and similar appearances were noted (Figs. 5 to 12). It was concluded therefore that the common observation of increased joint space was misleading and that it could usually be accounted for by the changed position of the femoral head after osteotomy.

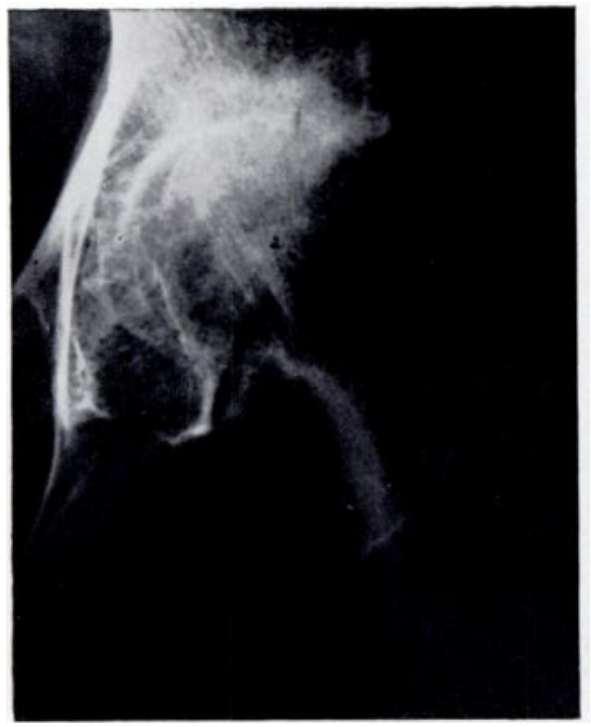

FiG. 18

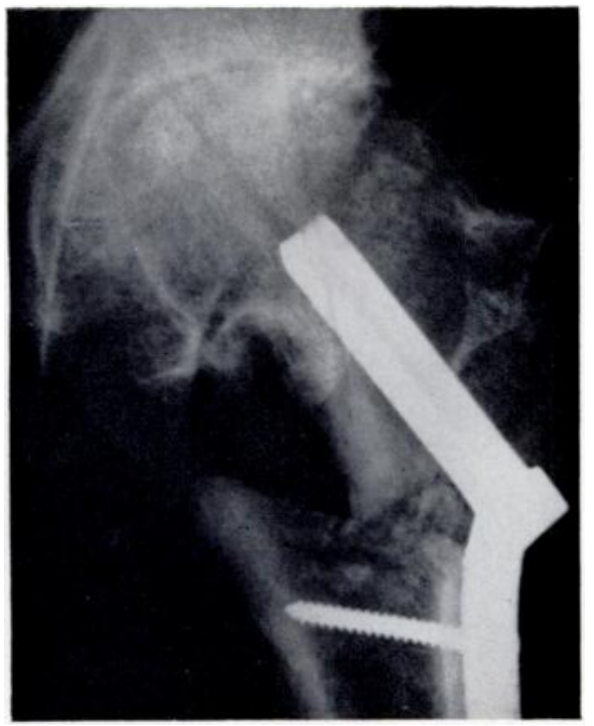

FIG. 19

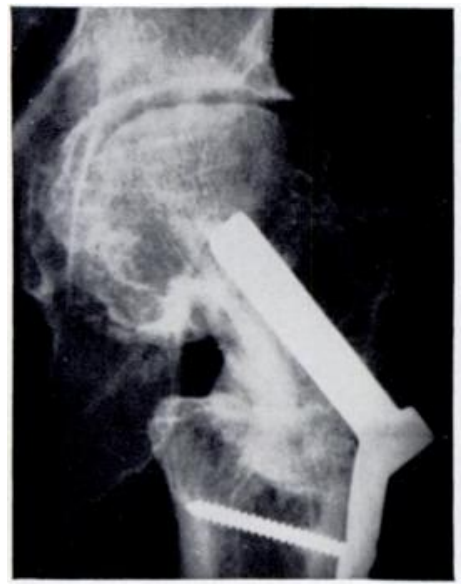

Fig. 20

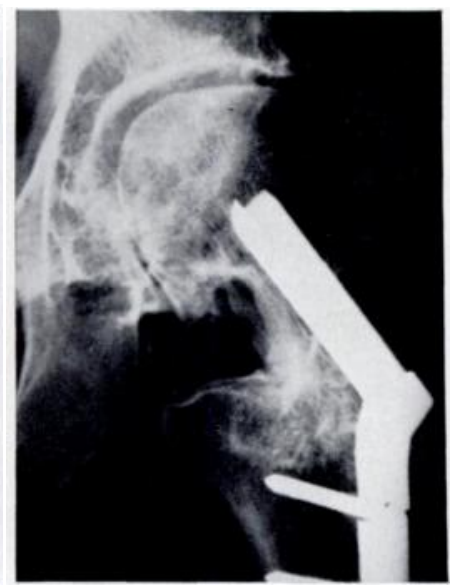

FIG. 21

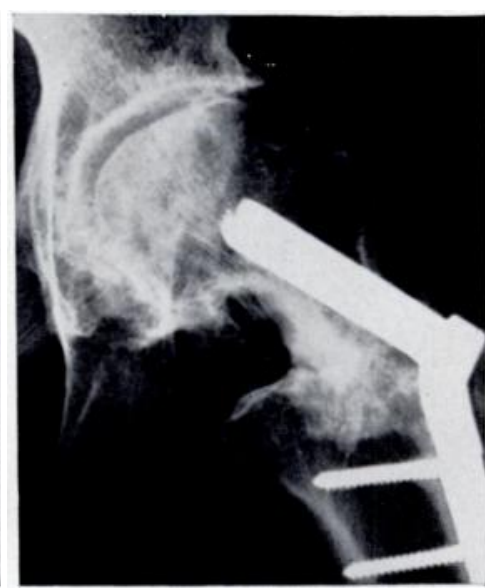

FiG. 22

Osteoarthritis of the hip showing slight apparent increase in joint space in the radiograph taken after operation and true increase in joint space in radiographs taken eighteen months after operation. Figure 18-Before operation. Figure 19-Immediately after operation. Figures 20 to 22 -The same hip eighteen months after operation. Figure 20-Medial rotation. Figure 21-Lateral rotation. Figure 22-Abduction.

However, in three patients further improvement took place after about eighteen months and here there is presumptive evidence that it was real because it was clearly visible in whatever positions of the hip the radiographs were taken. In these cases (Figs. 13 to 22) the increase in joint space and regression of osteoarthritic changes were striking.

vol. 42 B, No. 3, AUGUST 1960 


\section{CONCLUSIONS}

1. Nine out of ten patients who undergo McMurray osteotomy may expect lasting relief of pain. Seventy-five per cent should have a satisfactory functional result. It is rare for a patient to be made worse.

2. Osteoarthritis of the hip and ununited fracture of the femoral neck are good reasons for operation; avascular necrosis after fracture is not.

3. Internal fixation shortens the time in plaster and in hospital, and reduces the incidence of stiffness of the knee.

4. The common observation that the joint space may be increased after osteotomy is due often to the altered position of the femoral head. Occasionally there occurs a true increase in joint space, presumably indicating regeneration of articular cartilage, and an accompanying regression in the changes of osteoarthritis.

\section{REFERENCES}

Adam, A., and SPence, A. J. (1958): Intertrochanteric Osteotomy for Osteoarthritis of the Hip. Journal of Bone and Joint Surgery, 40-B, 219.

BAEYER, H. von (1918): Operative Behandlung von nicht reponierbaren angeborenen Hüftverrenkung. Münchener Medizinische Wochenschrift, 65, 1,216.

Burrows, H. J., Murley, A. H. G., and Shephard, E. (1955): Displacement Osteotomy for Osteoarthritis of the Hip: Results More Than Twenty Years Later. Journal of Bone and Joint Surgery, 37-B, 168.

Campbell, J. P., and JaCKson, J. P., (1955): The Treatment of Osteoarthritis of the Hip by Osteotomy. Journal of Bone and Joint Surgery, 37-B, 167.

CaPener, N. (1956): Reconstructive Surgery of the Hip Joint. In Modern Trends in Orthopaedics. (Second Series). Edited by Sir Harry Platt. London: Butterworth \& Co. (Publishers) Ltd.

LORENZ, A. (1919): Ueber die Behandlung der irreponiblen angeborenen Hüftluxationen und der Schenkelhalspseudoarthrosen mittels Gabelung. Wiener Klinische Wochenschrift, 32, 997.

McMurray, T. P. (1935): Osteo-arthritis of the Hip Joint. British Journal of Surgery, 22, 716.

McMurray, T. P. (1939): Osteo-arthritis of the Hip Joint. Journal of Bone and Joint Surgery, $21,1$.

Malkin, S. A. S. (1936): Femoral Osteotomy in Treatment of Osteo-arthritis of the Hip. British Medical Journal, i, 304.

Milch, H. (1947): Osteotomy of the Long Bones, p. 202. Oxford: Blackwell Scientific Publications Ltd.

OSBorne, G. V., and Fahrni, W. H. (1950): Oblique Displacement Osteotomy for Osteoarthritis of the Hip Joint. Journal of Bone and Joint Surgery, 32-B, 148.

Pauwels, F. (1935): Der Schenkelhalsbruch. Stuttgart: Ferdinand Enke.

SCHANZ, A. (1922): Zur Behandlung der veralteten angeborenen Hüftverrenkung. Münchener Medizinische Wochenschrift, 69, 930 .

ShePherd, M. M. (1954): Assessment of Function after Arthroplasty of the Hip. Journal of Bone and Joint Surgery, 36-B, 354.

Wardle, E. N. (1955): Displacement Osteotomy of the Upper End of the Femur. Journal of Bone and Joint Surgerv, 37-B, 568. 